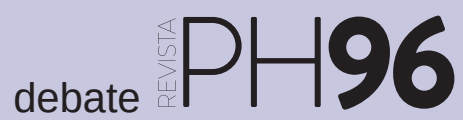

a debate Memoria democrática en la construcción de la historia y el patrimonio

| coordina Josefina Cuesta Bustillo

\title{
Memoria, patrimonio y ciudadanía: una contribución desde una perspectiva didáctica
}

Jesús Estepa Giménez | Dpto. de Didácticas Integradas, Universidad de Huelva

URL de la contribución <www.iaph.es/revistaph/index.php/revistaph/article/view/4299>

Cuando la revista me invitó a participar en este debate, entendí que lo que se esperaba de mí era una aportación desde una perspectiva educativa, pedagógica, o mejor didáctica y, en particular, de la didáctica de las ciencias sociales, área de conocimiento de la que soy profesor e investigador. Entiendo que tanto en algunas preguntas para el debate, como en el texto que lo presenta y en varias de las contribuciones que he podido leer, cabe el aporte de esta perspectiva, que puede facilitar una auténtica participación de la ciudadanía en la gestión y conservación de la memoria y de sus lugares/ espacios patrimoniales.

En lo que se refiere a las relaciones entre patrimonio, memoria y educación ciudadana, proponemos (ESTEPA; MARTÍN-CÁCERES, 2018) trabajarlas en el aula y en la formación inicial y permanente del profesorado mediante lo que denominamos antipatrimonio, uno de los subtipos de los que tratamos como patrimonios en conflicto. Con esta última denominación nos referimos a cuando el docente selecciona elementos patrimoniales no por sus valores estéticos o medioambientales, sino en atención a diversas causas que suscitan conflicto, ya sea de carácter ideológico, político, económico, carácter medioambiental o por interacción entre ellos. Esta selección intencionada tiene como fin propiciar en el alumnado habilidades y capacidades características del pensamiento crítico, la preocupación por estar y por permanecer bien informado, saber diferenciar hechos de opiniones, valorar la información y distinguir los intereses que favorecen cada opción, mantener la mente abierta para ser capaz de considerar puntos de vista divergentes al propio, tener flexibilidad para considerar alternativas y opiniones, honestidad para encarar los propios prejuicios, estereotipos y tendencias egocéntricas y/o sociocéntricas, $y$, por último, posicionamiento reflexivo para valorar los dilemas entre las tradiciones y la ética.

Con la enseñanza del antripatrimonio en particular, se trata de no olvidar las atrocidades cometidas en las guerras y en los conflictos violentos entre ciudadanos de un país o de varios países, constituyendo el patrimonio que engendraron otro elemento para educar históricamente en una ciudadanía no violenta, crítica y democrática. De este modo, se pueden establecer vínculos emocionales con las víctimas de esta barbarie, torturadas, asesinadas, represaliadas, marginadas o exiliadas, a través de las visitas presenciales/virtuales, historia oral o el análisis de documentación, preferentemente audiovisual, de los campos de concentración y exterminio nazi, como Dachau, Mauthausen y Auschwitz; las cárceles donde se ha torturado a presos políticos o miembros destacados de una etnia o confesión religiosa; los cementerios de víctimas de la I o II Guerra Mundial; Ios museos/centros de interpretación de la Inquisición; los centros de interpretación sobre el cambio climático, el genocidio judío, de la Paz en Guernika, de la Memoria y los Derechos Humanos en Santiago de Chile y Buenos Aires, o el Hirosima Peace Memorial Museum.

En el caso de España, la política sistemática contra la memoria histórica ha provocado la no consideración de cualquier patrimonio que pueda poner en cuestión el pasado franquista. Sin embargo, desde nuestra perspectiva, en la construcción de una historia con memoria, se debe trabajar con el alumnado -y no evitar por "falta de tiempo"- contenidos que van desde la Segunda República, pasando por la Guerra Civil, hasta la posguerra, incluyendo la implantación de la Dictadura, la violación sistemática de los derechos humanos de los vencidos, los desaparecidos, torturados, exiliados, pre- 
a debate Memoria democrática en la construcción de la historia y el patrimonio

| coordina Josefina Cuesta Bustillo

sos políticos, la expropiación de bienes, la represión de toda protesta, como parte de un proceso de educación para una ciudadanía crítica y comprometida con la memoria democrática de su pasado, los problemas del presente y la construcción de su futuro.

Así, tomando como ejemplo el Valle de los Caídos, una vez exhumados los restos de Franco y trasladados fuera del recinto, esta construcción debería reconvertirse en un memorial de las víctimas, no solo de la Guerra Civil, sino principalmente de la represión posterior. Solo así, podría considerarse un elemento patrimonial por los vínculos emocionales que se pueden establecer con las víctimas del franquismo. Como señalamos en un trabajo anterior sobre este monumento (DELGADO-ALGARRA; ESTEPA, 2014), este espacio alberga una serie de construcciones en torno a las cuales se genera una interpretación de la memoria dependiente del posicionamiento ideológico de los ciudadanos, de los usos que se hacen de los mismos y de los objetivos implícitos en cada posicionamiento. El profesorado tendría entonces en este elemento patrimonial un potente recurso didáctico para facilitar el análisis de la pluralidad mnemónica y de los intereses políticos e ideológicos implícitos en el mismo, de cara a educar a ciudadanos críticos y democráticos.

A modo de conclusión de esta breve aportación, reivindicamos que la educación puede suponer una contribución relevante para trabajar la memoria y sus huellas y testimonios a través del patrimonio. La atención en las víctimas, los disidentes, los olvidados, los vencidos y en los lugares de la memoria, significa otra manera de hacer historia y de enseñarla constituyendo un potente recurso didáctico, por un lado, en relación con los contenidos conceptuales, procedimentales y actitudinales y las competencias, como la empatía histórica, el trabajo con fuentes primarias y secundarias, la inteligencia emocional, la educación patrimonial y habilidades de pensamiento crítico y de análisis. Por otro lado, porque ante el empleo muy generalizado en la didáctica de la Historia de una metodología tradicional basada en la memorización de contenidos (ESTEPA, 2017), el tratamiento de estos temas controvertidos en el aula desde una posición de imparcialidad comprometida del docente hace necesario el uso de una metodología menos transmisiva por parte del profesorado y más activa en lo que se refiere al alumnado, para evitar el adoctrinamiento ideológico y favorecer actitudes reflexivas y críticas. Con estos nuevos contenidos y esta metodología más motivadora, se podrá alcanzar en la educación de los estudiantes un mayor compromiso con el presente, la comprensión de sus vínculos con el pasado y la reflexión sobre las posibles consecuencias que tienen determinados hechos y acciones en el futuro.

\section{BIBLIOGRAFÍA}

- DELGADO-AlgARRA, E. J.; ESTEPA, J. (2014) El Patrimonio como huella de la memoria histórica: análisis didáctico de dos monumentos en España y Japón. Clio: history and history teaching, n. ${ }^{\circ} 40,2014$

- ESTEPA, J. (2017) Otra didáctica de la Historia para otra Escuela. Huelva: Servicio de Publicaciones de la Universidad de Huelva, 2017

- ESTEPA, J.; MARTíN-CÁCERES, M. (2018) Competencia en conciencia y expresiones culturales y educación histórica. Patrimonios en conflicto y pensamiento crítico. En GÓMEZ CARRASCO, C. J.; MIRALLES, P. (coord.) La educación histórica ante el reto de las competencias. Métodos, recursos y enfoques de enseñanza. Barcelona: Octaedro, 2018, pp. 75-86 